\title{
Engagement in Hope as Well as Disorders: An Integrated Perspective of Positive Psychology and Peer Counseling
}

\author{
Qisheng Zhan ${ }^{1}$, Yuanyuan Liu ${ }^{1}$, Xiaoling Wang ${ }^{1} \&$ Jie Shang $^{2}$ \\ ${ }^{1}$ Institute of Psychology, Tianjin University, China \\ ${ }^{2}$ College of Management and Economics, Tianjin University, China \\ Correspondence: Qisheng Zhan, Institute of Psychology, Tianjin University, China. E-mail: zqs@tju.edu.cn
}

Received: March 26, 2014 Accepted: April 11, 2014 Online Published: May 26, 2014

doi:10.5539/ass.v10n12p114

URL: http://dx.doi.org/10.5539/ass.v10n12p114

\begin{abstract}
Psychological Monitors are the special social group that originated from mental health education in Chinese colleges. The working model of Psychological Monitors is similar to the peer counseling in the USA and European Countries. However, Psychological Monitors have their own characteristics which are related with the managerial institutions of Chinese colleges. This article integrates better foreign experience about peer guidance and constructs new working model of Psychological Monitors from the perspective of positive psychology. This model includes such contents as how to popularize positive mental health theories, how to carry positive mental health counseling into effect and how to build up positive mental states and corresponding behavioral patterns.
\end{abstract}

Keywords: positive psychology, mental health, psychological monitors, peer counseling

\section{From Peer Counselors to Psychological Monitors}

Peer counseling is a way of people's helping each other adjust to life events and helping solve each other's problems (Kramer, 1974). At one time, however, peer counseling has always existed on the fringes of medicine. The first organizations of peer counseling started in the 1940s, during the early years of the civil rights movement. Many more were launched in the 1960s and 1970s, inspired by the dogma and methodology of 12-step programs, New Age thinking and the general do-it-yourself ethos of that era. In those days, peer activists were waging an all-out war on psychiatry. Four decades later, peer counseling is about to become mainstream owing to the Patient Protection and Affordable Care Act of 2010 (Edmondson, 2012). Thus the history of peer counseling is more than seventy years. As far as the developmental process of peer counseling is concerned, it can be divided into at least three stages:

The first stage is that peer counseling mainly focuses on patients' treatment in early times. Peer counseling is long used in the human treatment of the mentally ill (Edmondson, 2012). Even nowadays, peer counseling is widely used for patients' treatment in inpatient wards. Peer counseling is still becoming an increasingly viable treatment option when working with people living with HIV/AIDS, especially during the diagnostic process. And the peer counseling mainly refers to as peer support counseling (Harris \& Larsen, 2007).

The second stage is that peer counseling is spread to a variety of schools including primary schools, high schools (McLaurin \& Harrington, 1977), colleges and universities (Morey \& Miller, 1993).

The third stage is that peer counseling become common activities in a variety of different sectors which comprise businesses, companies and factories. For example, implementation of peer counseling can be used as dietary intervention (Allicock, 2010), senior program (Garcia, Metha, Perfect, \& McWhirter, 1997), online chat service (Fukkink, 2011), healthful breastfeeding schedule (Peregrin, 2002).

However, Psychological Monitors emerged as peer counselors with Chinese characteristics in Tianjin University in China in 2004. Why has Psychological Monitor been founded as a social role? And how has it been developed all these years? Meanwhile, why did Psychological Monitors as class volunteers come into existence in Chinese colleges? Such problems are related to two aspects: one is the theory of peer psychological counseling, and the other is the special social background. Both problems will be discussed as follows:

First of all, peer counseling theories stress mutual help among the people with the same age. Peer help is meaningful for each individual's grow-up. There are three reasons. The first reason is that they have almost 
similar experiences because they live in the same times. The second reason is that all the activities they participate in are almost similar, too. The last one is that they share common interests in things of all sorts.

Secondly, special social background affects peer's mental states. There are a great many special incidents for each epoch. For example, serious suicide and violence and mental disorders such as Schizophrenia should be paid attention for us all. Especially, in 2004 one senior college student in Yunnan University killed four of his classmates, which rocked the whole country even the world. And the suicide of college students in Chinese high education institutes should be coped with by professional teachers as well as nonprofessional students.

On the top of all, peer counseling is the positive activities of soul-to-soul. The peer counselors have established good interpersonal relationships through a great many psychological counseling conversation skills which consist of at least twenty kinds, which include the skills of asking questions, encouraging, repeating, responding to contents or emotions, self-opening, expressing contents or emotions, and so on.

On the basis of such reasons, Psychological Monitors gradually become an important role in college management affairs in China.

\section{The Working Model of Psychological Monitors}

After the birth of psychological monitors, psychological knowledge has been infused into college students through a particular pathway which is available in Chinese colleges. Thus a new preventable measure about mental problems has been coming into being.

Firstly, Psychological Monitors should be selected carefully. What characteristics are Psychological Monitors demanded to have? Actually, the screening of potential peer counselors did not stress their academic ability. Rather, we focused on attitudes and sense of responsibility (Goodman, 1971), the ability to follow instructions, flexibility, and the ability to work under adverse conditions (Pope, 1970), in establishing our selection criteria (McLaurin \& Harrington, 1977).

Secondly, Psychological Monitors need to be trained systematically and regularly. During the training period, the scientific knowledge system has been provided which usually include six branches of psychology. The six branches include basic psychology, social psychology, developmental psychology, abnormal psychology, counseling psychology and psychometrics. In each branch we list at least 15 sentences about this subject.

The interpretation of each psychological term in the field of psychology should be coherent and intelligible for psychological monitors. For example, schizophrenia means that the client possibly has symptoms of illusions (see or hear some things which don't exist really in our life), illogical remarks, paranoia, and etc.; Suicide is referred to as someone killed innocent client himself; Neurasthenia is a kind of mental illness which is mental easily excited and mental fatigue easily and insomnia.

After peer counselors have been trained and have passed the examination for qualification, they have come to work with their classmates. And they will be praised with some honorary certificates if they have excellent performance.

Generally speaking, the generic model of Psychological Monitors can be illustrated in Figure 1 as follow:

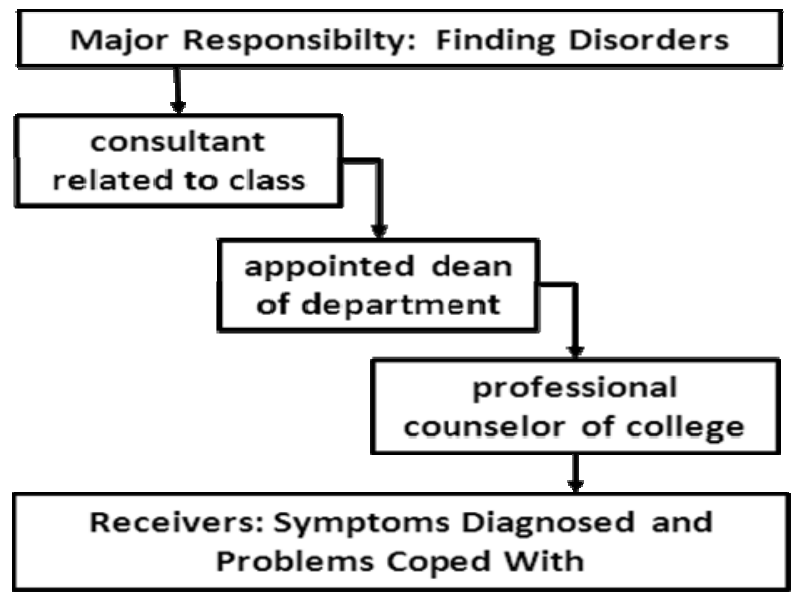

Figure 1. Generic working model of psychological monitors 
In this generic working model of psychological monitors, we can see the working program of psychological monitors. Their key duty as a social role is to find disorders of the people living around them. If they find someone presents some suspicious symptoms of a certain mental disorder, they should report to tutor first, or directly report to the dean of his/her faculty or the director of Psychological Counseling Center.

This model belongs to a problem-oriented coping model. Although it is simple and has no orientation of positive psychology, it is still useful and used at a large scope in colleges and universities of all sorts.

\section{Reform of the Working Model of Psychological Monitors Based on the Perspective of Positive Psychology}

New things are emerging day after day, and the psychological knowledge correspondently develops day after day, too. How can psychological monitors keep in pace with new things and especially new psychological knowledge?

Positive psychology has been founded by Seligman in 1990s. The working model of Psychological Monitors can be re-established according to the theory of positive psychology.

\subsection{Benefits of Peer Counseling and Fostering the Hope of People (Classmates)}

The study of hope, as an important psychosocial aspect of health, has exploded over the past two decades (Eliott, 2005). Roles and benefits of peer counseling, in relation to the facilitation of hope for people living with HIV/AIDS, suggest potentially interesting implications (Harris \& Larsen, 2007). According to this principle, we can infer that an excellent Psychological Monitor should play roles and benefits of peer counseling, in relation to the facilitation of hope for his/her classmates living with depression.

As a matter of fact, all those students committing suicides are hopeless to their future. At the same time, college students suffering depression and related mental illnesses also feel disappointed and hopeless to their development. Psychological Monitors' first responsibility as a social role should be "let each classmate be full of hope in the mind". We all live with hope.

\subsection{Contribution of the Peer Counselors and Multidimensional Social Support}

Many young people find support from their peers on the Internet. In a recently launched one-on-one chat service for young people with psychosocial problems, young peer volunteers aged 16-23 have a leading role in the conversations, comparable to the role of counselors in web-based and telephone-based child help-line services. A content analysis of the chat conversations showed that the contribution of the peer counselors in the confidential chat sessions satisfied the various quality criteria of the service. Moreover, the peer counselors offered the young people who visited the site varied types of social support. A variety of social support appeared a stronger predictor of the quality ratings than the length of the conversation or the quantity of social support, which emphasizes the importance of multidimensional social support in online conversations (Fukkink, 2011).

In a word, peer counselors in the United States are the same as Psychological Monitors in China. And peer counseling is also the same as peer support. Meanwhile, the peer support belongs to multidimensional social support. For instance, provide support by means of face-to-face communication, or communicate via cell phone, e-mail, QQ, Renren virtual social website, and etc. Especially all Psychological Monitors should utilize all kinds of communicative pathways to spread the knowledge of mental health care from the positive psychology.

\subsection{Serve Others with Similar Problems}

Peer counseling is now an approach to rehabilitation and treatment for mentally ill individuals in the U.S. In the mental health community, a peer means someone with a psychiatric condition who serves others with similar problems.

Every Psychological Monitor in the colleges has the same experience with his/her classmates. She/he can serve his/her classmates through a great many methods. For example, publicize the hotline of psychological counseling, and recommend psychological counselors to classmates if needed, and persuade or tell his/her classmates to think about anything from the perspective of positive psychology. It is enough for his/her work only if he/she does one of these issues mentioned above. 


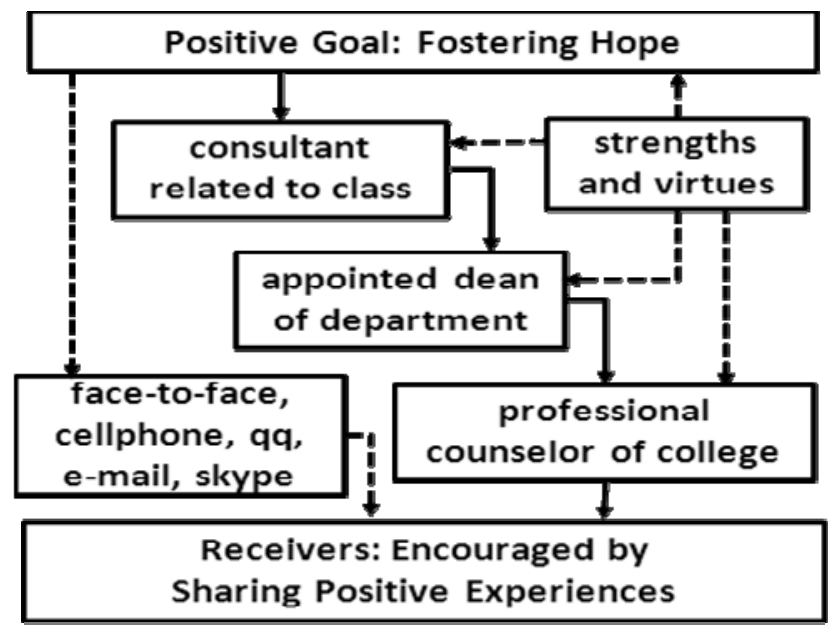

Figure 2. Positive working model of psychological monitors

Whether Psychological Monitors can solve their peers' similar problems or not completely depend on their positive experiences. That is also meaningful for determining who can be qualified for the position of Psychological Monitors.

To sum up, the core of Psychological Monitors' support is to share positive experience.

According to the three aspects of above contents about Psychological Monitors' positive working model, we can use Figure 2 to interpret the simple operating flow diagram. This model is more significantly improved than traditional model in Figure 1. However, the Figure 2 is full of contemporary characteristics of our times, and more practical. Strengths and virtues have been stressed in Figure 2.

With the popularization of this model, it will gradually become compulsory subject in Psychological Monitors' prevocational training. And it will lead to more enlightened consequences, which means more and more college students will become more optimistic than before through Psychological Monitors' work.

\section{Acknowledgements}

This study is supported by the Independent Innovation Fund of Tianjin University "Matching between Ideological and Political Education Methods and Psychological Counseling Skills in the Internet Age" (2014XSC-0008) and the "Twelfth Five-year" Planning Issue of Educational Sciences in Tianjin (HE4103).

\section{References}

Allicock, M., Campbell, M. K., Valle, C. G., Barlow, J. N., Carr, C., Meier, A., \& Gizlice, Z. (2010). Evaluating the implementation of peer counseling in a church-based dietary intervention for African Americans. Patient Education \& Counseling, 81(1), 37-42. http://dx.doi.org/10.1016/j.pec.2009.11.018

Edmondson, B. (2012). Crazy Enough to Care: Peer counseling, long used in the humane treatment of the mentally ill, is getting new attention as a cost saver because of the affordable care act. American Scholar, $81(2), 46-55$.

Eliott, J. A. (2005). What have we done with hope? A brief history. In J. A. Eliott (Ed.), Interdisciplinary Perspectives on Hope (pp. 3-45). New York: Nova Science Publishers.

Fukkink, R. (2011). Peer Counseling in an Online Chat Service: A Content Analysis of Social Support. Cyber Psychology. Behavior \& Social Networking, 14(4), 247-251. http://dx.doi.org/10.1089/cyber.2010.0163

Garcia, Y. E., Metha, A., Perfect, M. C., \& McWhirter, J. J. (1997). A senior peer counseling program: Evaluation of training and benefits to counselors. Educational Gerontology, 23(4), 329-344. http://dx.doi.org/10.1080/0360127970230403

Goodman, L. (1971). Tutoring for credit. American Education, 7, $26-27$.

Harris, G. E., \& Larsen, D. (2007). HIV Peer Counseling and the Development of Hope Perspectives from Peer Counselors and Peer Counseling Recipients. AIDS Patient Care \& STDs, 21(11), 843-860. http://dx.doi.org/10.1089/apc.2006.0207 
Kramer, D. (1974). High School Peer Counseling. Personnel \& Guidance Journal, 53(4), 330.

McLaurin, R., \& Harrington, J. (1977). A High School Instructional Peer-Counseling Program. Personnel \& Guidance Journal, 55(5), 262-265. http://dx.doi.org/10.1002/j.2164-4918.1977.tb04472.x

Morey, R. E., \& Miller, C. D. (1993). High school peer counseling: The relationship between student satisfaction and peer counselors' style of helping. School Counselor, 40(4), 293-300.

Peregrin, T. (2002). Education, Peer Counseling, and Paternal Support: Three Ways to Encourage a Healthful Breastfeeding Schedule. Journal of the American Dietetic Association, 102(7), 943. http://dx.doi.org/10.1016/S0002-8223(02)90215-4

Pope, L. (1970). Blueprint for a successful paraprofessional tutorial program. American Journal of Orthopsychiatry, 40, 229-300.

\section{Copyrights}

Copyright for this article is retained by the author(s), with first publication rights granted to the journal.

This is an open-access article distributed under the terms and conditions of the Creative Commons Attribution license (http://creativecommons.org/licenses/by/3.0/). 